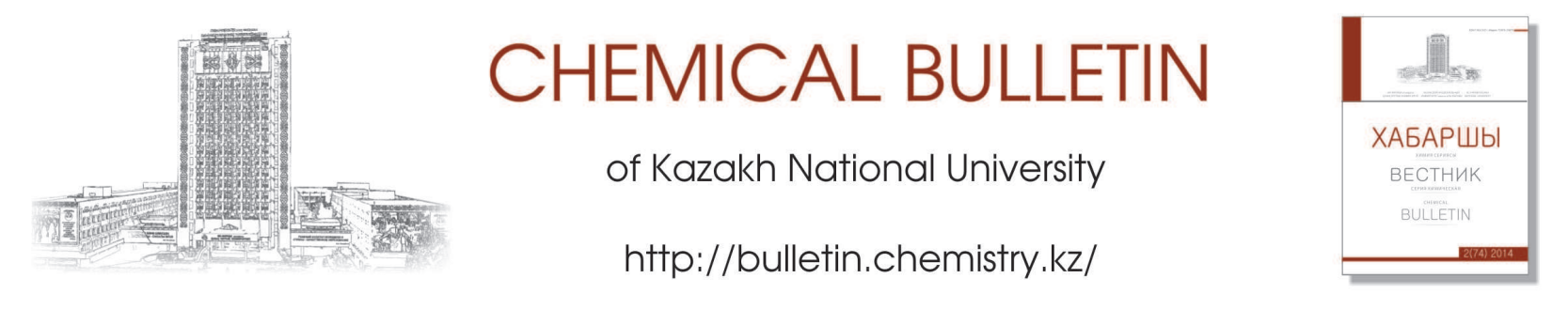

УДК 546.3

http://dx.doi.org/10.15328/chemb_2014_287-92

\title{
Н.Т. Шайкиева
}

Кыргызско-Турецкий университет «Манас», Кыргызстан, г. Бишкек

E-mail: nurshay@mail.ru

\section{Исследование фазовых равновесий \\ в тройной системе «формиат меди - формамид - вода»}

\begin{abstract}
Изотермическим методом исследована растворимость в системе $\mathrm{Cu}(\mathrm{HCOO})_{2}-\mathrm{HCONH}_{2}-\mathrm{H}_{2} \mathrm{O}$ при $25^{\circ} \mathrm{C}$. В системе установлен концентрационный интервал кристаллизации нового конгруэнтно растворимого соединения состава $2 \mathrm{Cu}(\mathrm{HCOO})_{2} \cdot \mathrm{HCONH}_{2} \cdot 4 \mathrm{H}_{2} \mathrm{O}$. Индивидуальность нового соединения подтверждена методами рентгенофазового, термического и ИК-спектроскопического анализа. В комплексном соединении координация формамида осуществляется через атом кислорода карбонильной группы. Показано, что термолиз комплексного соединения является сложным многостадийным процессом, включающим стадии дегидратации, разложения комплекса и образования оксида металла. Рассчитаны параметры элементарной ячейки a, B, c, hkl, величины межплоскостных расстояний и относительных интенсивностей.
\end{abstract}

Ключевые слова: формамид; формиат меди; водная система; растворимость; ИК-спектр; термический анализ.

\author{
Н.Т. Шайкиева \\ Фазалық тепе-теңдіктердің үш мәртелі \\ “мыс формиаты - формамид - су” жүйесінде зерттеу
}

Изотермиялық әдіспен $25^{\circ} \mathrm{CCu}(\mathrm{HCOO})_{2}-\mathrm{HCONH}_{2}-\mathrm{H}_{2} \mathrm{O}$ жүйесінің ерігіштігі зерттелді. Жүйеде жаңа конгруэнтті ерігіштік құралымының $2 \mathrm{Cu}(\mathrm{HCOO})_{2} \cdot \mathrm{HCONH}_{2} \cdot 4 \mathrm{H}_{2} \mathrm{O}$ кристалдануының концентрациялық интервалы анықталды. Жаңа қосылыстың даралығы рентгенфазалық, термиялық және ИК-спектроскопиялық сараптамалары бойынша дәлелденді. Комплекстік қосылыста формамидтың координациясы карбонил топтың оттегі арқылы жүзеге асады. Комплекстік қосылыстың термолизі күрделі көп сатылы дегидратация, оксид металдың түзілуін және комплекстің ыдырауын қосатын үрдіс болып табылды. Элементарлық ұяшықтың a, в, c, hkl параметрлері есептелді, жазықтық аралығының көлемі және салыстырмалы үнемділігі анықталды.

Tүйін сөздер: формамид; мыс формиаты; сулы жүйе; ерігіштік; ИК-спектр; термиялық анализ.

\author{
Shaykieva N.T. \\ Study of phase equilibria in the ternary \\ "copper formate - formamide -water" system
}

The solubility in $\mathrm{Cu}(\mathrm{HCOO})_{2}-\mathrm{HCONH}_{2}-\mathrm{H}_{2} \mathrm{O}$ system at $25^{\circ} \mathrm{C}$ was studied by isothermal method. In this system concentration range of crystallization of new congruently soluble compound of $2 \mathrm{Cu}(\mathrm{HCOO})_{2} \cdot \mathrm{HCONH}_{2} \cdot 4 \mathrm{H}_{2} \mathrm{O}$ was found. The presence of the new compound was determined using X-ray analysis, thermal analysis and IR spectroscopic method. Coordination of formamide occurs through oxygen atom of a carbonyl group in complex compound. Thermolysis of complex compounds was shown to be multistage process involving the dehydration step, decomposition of the complex, metal oxide formation. The unit cell parameters a, b, c, hkl, values of interplanar spacings and relative intensities have been calculated.

Key words: formamide; copper formate; aqueous system; solubility; IR spectrum; thermal analysis. 


\section{Введение}

В современной химии получение биологически активных комплексных веществ является актуальной задачей. Комплексные твердые смеси используются в качестве удобрений и симуляторов роста растений [1].

Формамид является физиологически активным органическим лигандом, за счет атомов амидного азота и кислорода карбоксильной группы образует большое число комплексных соединений. Медь входит в число биологически значимых элементов. Микроэлементы с биоактивными лигандами являются наиболее приближенными к их состоянию в живом организме.

Формамид и его производные образуют различные комплексы с солями переходных металлов, так, например, получены и исследованы свойства комплексов формамида с нитратами, формиатами и галогенидами многих металлов [2-4]. За последнее время биологически активные комплексные соединения активно используются в сельском хозяйстве. Авторами работ [5, 6] проведены полевые испытания, полученные формамидные комплексные соединения были рекомендованы как стимулятор роста растений для повышения урожайности корнеплодов.

Данные о взаимодействии формиата меди с формамидом в водной среде в литературе отсутствуют. Ранее нами было синтезировано комплексное соединение $\mathrm{Zn}(\mathrm{HCOO})_{2} \cdot \mathrm{HCONH}_{2}$ $\cdot \mathrm{H}_{2} \mathrm{O}$, выращены его кристаллы и изучены его свойства физико-химическими методами [7].

Цель настоящей работы - исследование фазовых равновесий в системе $\mathrm{Cu}(\mathrm{HCOO})_{2}-$ $\mathrm{HCONH}_{2}-\mathrm{H}_{2} \mathrm{O}$ при $25^{\circ} \mathrm{C}$ и установление области кристаллизации нового комплексного соединения на основе формамида, формиата меди и воды, изучение их свойств методами физико-химического анализа и изыскание областей применения в сельском хозяйстве и животноводстве.

\section{Эксперимент}

Исследование растворимости в системе $\mathrm{Cu}(\mathrm{HCOO})_{2}-\mathrm{HCONH}_{2}-\mathrm{H}_{2} \mathrm{O}$ проводили при $25^{\circ} \mathrm{C}$ методом изотермической растворимости. Равновесие в системе при непрерывном перемешивании смесей устанавливалось в течение 7-8 ч. В качестве исходных веществ использовали формамид марки «х.ч», $\mathrm{Cu}(\mathrm{HCOO})_{2} \cdot 2 \mathrm{H}_{2} \mathrm{O}$ синтезировали из нитрата меди $\mathrm{Cu}\left(\mathrm{NO}_{3}\right)_{2}$ и муравьиной кислоты марки «ч.д.а». Жидкие и твердые фазы анализировали на содержание амидного азота по методу Кьельдаля, а ион меди - трилонометрически в аммиачном растворе в присутствии мурексида в качестве индикатора [8].

Установление состава твердых фаз, кристаллизующихся в системах, проводили методом “остатков” Скрейнемакерса [9].

ИК-спектры соединений в области 4000400 см$^{-1}$ снимали на спектрофотометре FT-IR Model-400, Nicollet в образцах, таблетированных с KBr.

Дифрактограммы снимали на приборе ДРОН-3, на кобальтовом излучении при напряжении 30 кВ и анодном токе 30 А. Скорость сканирования составляла 1 град/мин. Термогравиметрический анализ проводили на дериватографе STA 449 F3, системы Паулик-ПауликЭрдей. Скорость нагрева - 10 К/мин.

\section{Результаты и обсуждения}

Изотерма растворимости системы $\mathrm{Cu}(\mathrm{HCOO})_{2}-\mathrm{HCONH}_{2}-\mathrm{H}_{2} \mathrm{O}$ (рисунок 1) характеризуется двумя ветвями кристаллизации: дигидрата формиата меди и нового соединения $2 \mathrm{Cu}(\mathrm{HCOO})_{2} \cdot \mathrm{HCONH}_{2} \cdot 4 \mathrm{H}_{2} \mathrm{O}$. Данное соединение кристаллизуется в концентрационных интервалах по формиату меди 9,58-18,59 масс. $\%$ и по формамиду 6,3 - 3,65 масс. \%. Установленное соединение в воде растворяется конгруэнтно, так как линия, соединяющая полюсы соединения и воды, пересекает линию насыщения комплекса. Формамид как жидкое вещество не имеет ветви кристаллизации.

В системе $\mathrm{Cu}(\mathrm{HCOO})_{2}-\mathrm{NH}\left(\mathrm{CONH}_{2}\right)_{2}-\mathrm{H} 2 \mathrm{O}$ при 250С [10] установлено образование инконгруэнтнорастворимого соединения с соотношением компонентов $\mathrm{Cu}(\mathrm{HCOO})_{2}: \mathrm{NH}\left(\mathrm{CONH}_{2}\right)_{2}$, равным 1:2. Соединение кристаллизуется из насыщенных равновесных растворов системы при меньшем содержании как формиата меди, так и амида кислоты. В системе с участием формамида не наблюдается дегидратации исходной соли меди, как и в системе с формиатом цинка [7].

ИК-спектроскопическое исследование проводили с целью определения характера координации молекул формамида с металлом - комплексообразователем (рисунок 2).

При сравнении ИК-спектров соединения $2 \mathrm{Cu}(\mathrm{HCOO})_{2} \cdot \mathrm{HCONH}_{2} \cdot 4 \mathrm{H}_{2} \mathrm{O}$ и свободного формамида наблюдаются следующие различия: полоса поглощения валентного колебания карбонильной группы $v(\mathrm{C}=\mathrm{O})$ смещена в низкочастотную область - от 1695 до 1657 см-1, и полосы 


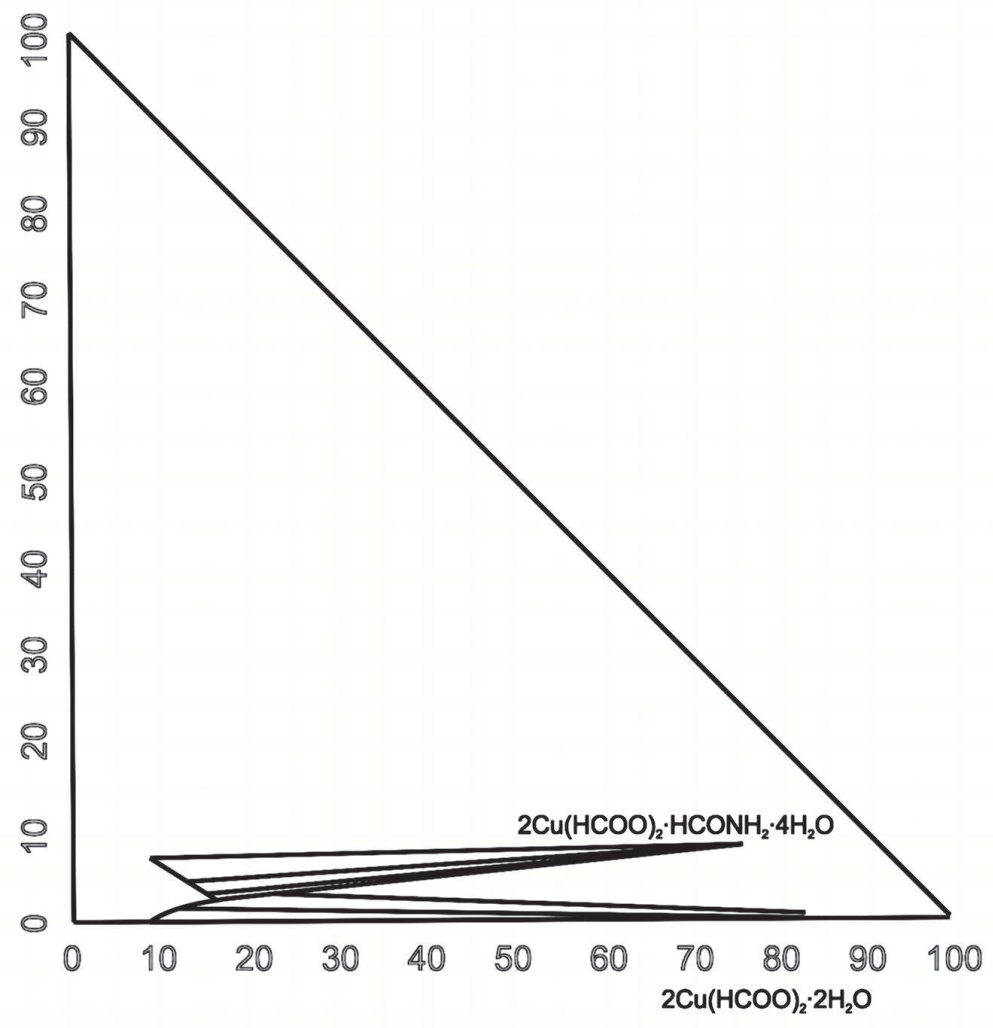

Рисунок 1 - Диаграмма растворимости системы $\mathrm{Cu}(\mathrm{HCOO})_{2}-\mathrm{HCONH}_{2}-\mathrm{H}_{2} \mathrm{O}$ при $25^{\circ} \mathrm{C}$

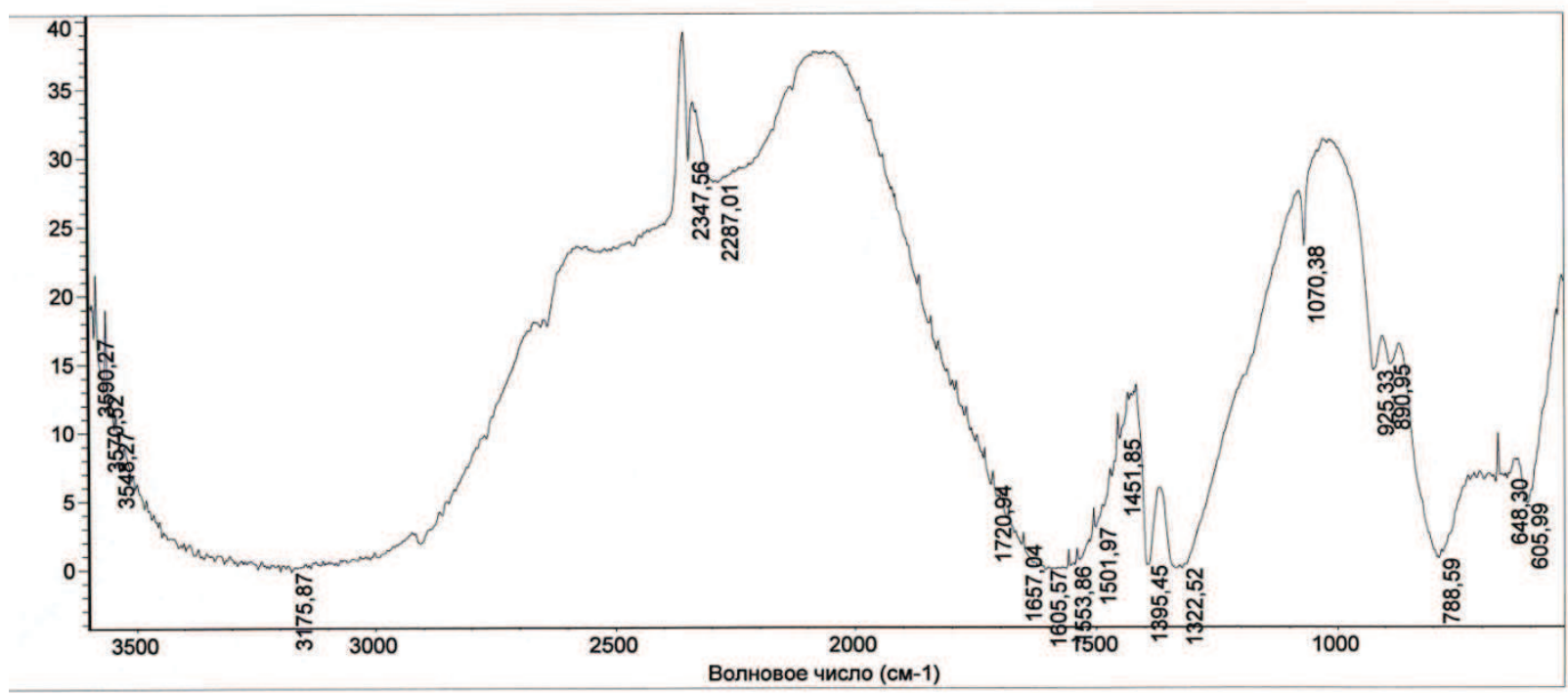

Рисунок 2 - ИК-спектры поглощения соединения $2 \mathrm{Cu}(\mathrm{HCOO})_{2} \cdot \mathrm{HCONH}_{2} \cdot 4 \mathrm{H}_{2} \mathrm{O}$

валентных колебаний $v(\mathrm{CN})$ смещены в высокочастотную область от 1309 до $1322 \mathrm{~cm}^{-1}$. Такие изменения в спектре соединения указывают на ослабление $\mathrm{C}=\mathrm{O}$ связи и упрочнение $\mathrm{C}-\mathrm{N}$ связи. Это говорит о том, что координация формамида осу- ществляется через кислород. В спектре деформационного колебания $\delta(\mathrm{OCN})$ амида наблюдается высокочастотное смещение полосы от 600 до 648 $\mathrm{cm}^{-1}$, по-видимому, происходит образование координационной связи с металлом [11]. 
В работах $[7,10]$ показано, что в формамидных и аллофанамидных комплексах формиатов металлов меди, цинка координация осуществляется через кислород карбоксильной группы соответствующего амида.

На дериватограмме комплексного соединения $2 \mathrm{Cu}(\mathrm{HCOO})_{2} \cdot \mathrm{HCONH}_{2} \cdot 4 \mathrm{H}_{2} \mathrm{O}$ имеются несколько термических эффектов (рисунок 3 ). Первый эндотермический эффект начинается при $70-120^{\circ} \mathrm{C}$, это объясняется началом плавления комплекса и удаления адсорбированной влаги, убыль массы при этом составляет 17,66\%. При температурах $210-250^{\circ} \mathrm{C}$ происходит экзотермический эффект, здесь формамид полностью разлагается на аммиак и углекислый газ, также начинается разложение формиата меди, убыль массы - 45,14\%. Далее с повышением температуры происходит разложение на карбонат и оксид меди, убыль массы - 4,44\%.

В таблице 1 приведены данные рентгенофазового анализа комплекса формамида с формиатом меди, которые подтверждают образование нового комплекса, характеризующегося собственным набором межплоскостных расстояний.

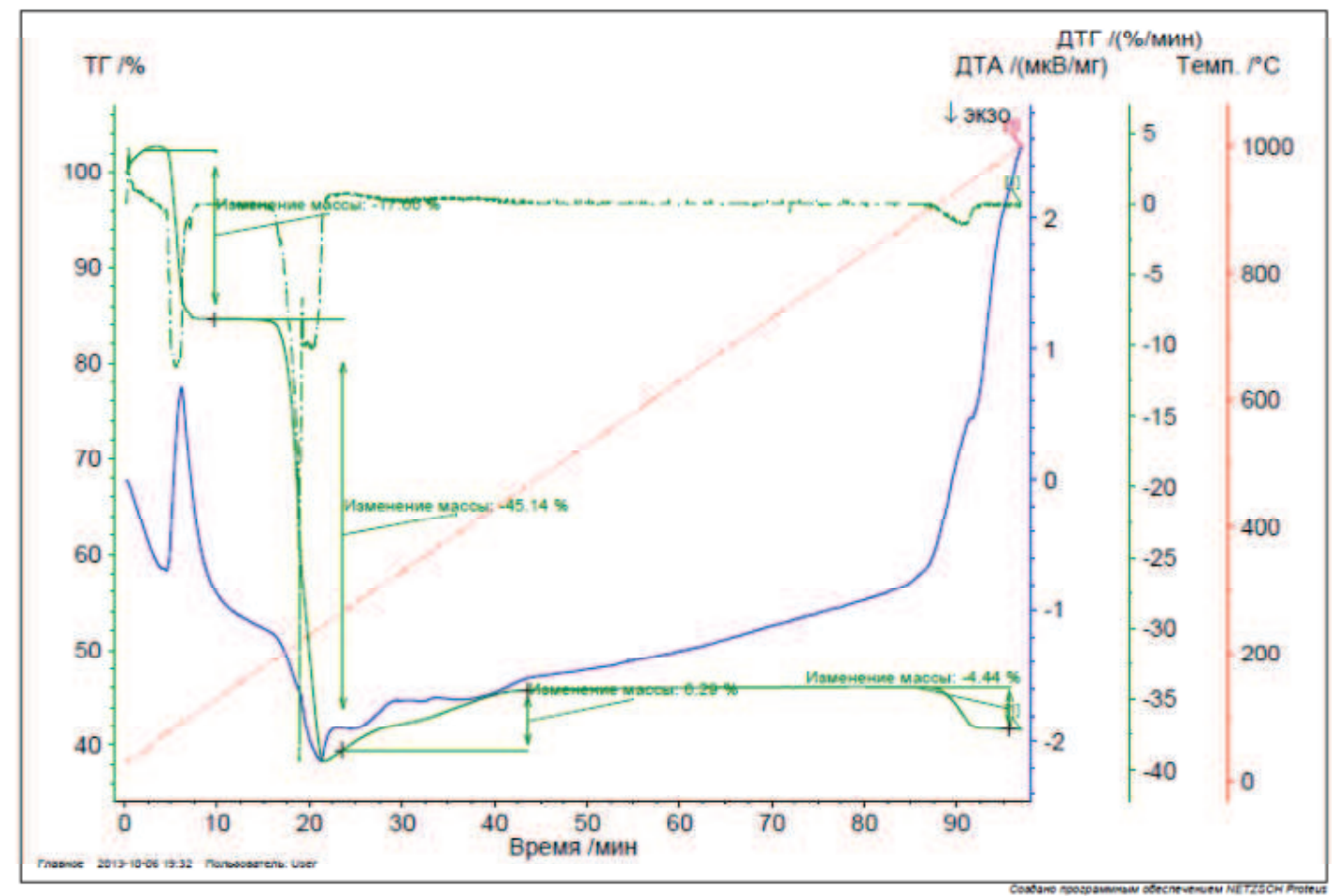

Рисунок 3 - Дериватограмма соединения $2 \mathrm{Cu}(\mathrm{HCOO})_{2} \cdot \mathrm{HCONH}_{2} \cdot 4 \mathrm{H}_{2} \mathrm{O}$

\section{Заключение}

Исследования по изучению фазовых равновесий в системе с участием формиата меди, формамида и воды установили образование конгруэнтно растворимого нового соединения $2 \mathrm{Cu}(\mathrm{HCOO})_{2} \cdot \mathrm{HCONH}_{2} \cdot 4 \mathrm{H}_{2} \mathrm{O}$. Кристаллизация данного соединения соответствует концентрациям по формиату меди 9,58-18,59 масс. \% и по формамиду 6,3 - 3,65 масс. \%. В комплексе металл - комплексообразователь с лигандом соединяется через атом кислорода, так как наблю- дается понижение частот валентных колебаний $v \mathrm{C}=\mathrm{O}\left(\right.$ на $\left.38 \mathrm{~cm}^{-1}\right)$ и повышение частот валентных колебаний $v \mathrm{C}-\mathrm{N}$ (на $13 \mathrm{~cm}^{-1}$ ). Рентгенограмма нового соединения содержит линии, которые ни по интенсивности, ни по значениям межплоскостных расстояний не совпадают с набором линий для лиганда, и по результатам рентгенофазового анализа установлено, что новое комплексное соединение имеет ромбическую сингонию, параметры ячейки которой равны с $=11,6624 \mathrm{~A} 0 ;$ в $=$ 9,7798 A0; a = 9,3874 A0 . 
Таблица 1 - Данные рентгенофазового анализа комплексного соединения $2 \mathrm{Cu}(\mathrm{HCOO})_{2} \cdot \mathrm{HCONH}_{2} \cdot 4 \mathrm{H}_{2} \mathrm{O}$

\begin{tabular}{|c|c|c|c|c|}
\hline \multicolumn{5}{|c|}{$2 \mathrm{Cu}(\mathrm{HCOO})_{2} \cdot \mathrm{HCONH}_{2} \cdot 4 \mathrm{H}_{2} \mathrm{O}$} \\
\hline $\mathrm{d}, \mathrm{A}^{0}$ & & $\Delta \mathrm{d}, \mathrm{A}^{0}$ & $\mathrm{I} / \mathrm{I}_{0}, \%$ & $\mathrm{hk}$ \\
\hline 5,8312 & 5,8321 & $-0,0009$ & 6,55 & 002 \\
\hline 4,8899 & 4,8911 & $-0,0012$ & 100 & 200 \\
\hline 4,6937 & 4,6984 & $-0,0047$ & 59,01 & 021 \\
\hline 4,5691 & 4,5129 & 0,0562 & 84,83 & 210 \\
\hline 4,2341 & 4,2371 & $-0,003$ & 34,42 & 202 \\
\hline 3,6430 & 3,6588 & $-0,0158$ & 9,83 & 103 \\
\hline 3,5046 & 3,5944 & $-0,0898$ & 26,22 & 113 \\
\hline 3,4295 & 3,4279 & 0,0016 & 69,67 & 130 \\
\hline 3,3380 & 3,3748 & $-0,0368$ & 12,29 & 032 \\
\hline 3,0659 & 3,0816 & $-0,0157$ & 16,43 & 231 \\
\hline 2,8402 & 2,8467 & $-0,0065$ & 6,55 & 005 \\
\hline 2,6237 & 2,6117 & 0,012 & 35,24 & 233 \\
\hline 2,3395 & 2,3325 & 0,007 & 1,22 & 304 \\
\hline 2,2052 & 2,2064 & $-0,0012$ & 2,86 & 026 \\
\hline 2,1301 & 2,1334 & $-0,0033$ & 1,22 & 244 \\
\hline 1,8039 & 1,8065 & $-0,0026$ & 26,22 & 1,22 \\
\hline 1,7571 & 1,7405 & 0,0166 & & \\
\hline
\end{tabular}

\section{Литература}

1 Набиев М.Н., Беглов Б.М., Тухтаев С. Формамид и удобрения на его основе. - Ташкент: ФАН, 1986. - 106 с.

2 Палкина К.К., Орлова В.Т., Смоленцев А.Ю., Фролова Е.А. Координационные соединения нитратов переходных металлов с формамидом $\mathrm{M}^{\mathrm{II}}\left(\mathrm{NO}_{3}\right)_{2} \cdot 2\left(\mathrm{HCONH}_{2}\right) \cdot 2 \mathrm{H}_{2} \mathrm{O}\left(\mathrm{M}^{\mathrm{II}}=\mathrm{Cu}, \mathrm{Cd}, \mathrm{Co}, \mathrm{Mn}\right) / /$ Журнал неорганической химии. - 2004. - T.49, №2. - С.197-201.

3 Кадыркулова С.О., Ахматова Ж.Т., Сулайманкулов К.С. Исследование взаимодействия формиата иттрия с формамидом // Химический журнал Казахстана. - Алматы. - 2004. - №1(2). - С.133-138.

4 Сапалова С.А. Взаимодействие сульфата меди с амидами // Вестник Иссык-Кульского университета. - 2010. - I часть. - C. 212-217.

5 Фролова Е.А., Орлова В.Т., Данилов В.П. Взаимодействие в системе $\mathrm{Mn}\left(\mathrm{NO}_{3}\right)_{2}-\mathrm{HCONH}_{2}-\mathrm{H}_{2} \mathrm{O} / /$ Журнал неорганической химии. - 2008. - Т.53, №6. - С.1017-1019.

6 Фролова Е.А., Данилов В.П. Изотерма растворимости системы $\mathrm{Zn}\left(\mathrm{NO}_{3}\right)_{2}-\mathrm{HCONH}_{2}-\mathrm{H}_{2} \mathrm{O}$ при $25^{\circ} \mathrm{C} / /$ Журнал неорганической химии. - 2009. - Т.54, №11. - С.1907-1909.

7 Шайкиева Н.Т., Ахматова Ж.Т. $25{ }^{\circ} \mathrm{C}$ да $\mathrm{Zn}(\mathrm{HCOO})_{2}-\mathrm{HCONH}_{2}-\mathrm{H}_{2} \mathrm{O}$ системасындагы фазалык тең салмактуулук // Республиканская научно-практическая конференция: «Химия. Химическая технология. Проблемы и перспективы». - Кыргызстан. Бишкек. - 2013 (в печати).

8 Шварценбах Г., Флашка Г. Комплексонометрическое титрование. - М.: Химия, 1970. - 251 с.

9 Михеева В.И. Метод физико-химического анализа в неорганическом синтезе. - М.: Наука, 1975. - 100 с.

10 Турсуналиева К.С., Ахматова Ж.Т., Сулайманкулов К.С. Равновесие в системе формиат меди - биурет - вода при $25^{\circ} \mathrm{C} / /$ Сборник научных трудов Биолого-почвенного института НАН КР «Исследование живой природы Кыргызстана».Бишкек, 2000. - С.160-164.

11 Иманакунов Б.И., Ким Т.П., Байдинов Т. Реакции формамида и диметилформамида с неорганическими солями. Фрунзе: Илим, 1986. -178 с. 


\section{References}

1 Nabiev MN, Beglov BM, Tukhtaev C (1986) Formamide and fertilizers based on it [Formamid i udobreniya na ego osnove]. FAN, Tashkent, Uzbekistan. (In Russian)

2 Palkina KK, Orlova BT, Smolentsev AYu, Frolova EA (2004) Russian Journal of Inorganic Chemistry 49:157-161.

3 Kadyrkulova SO, Ahmatova ZhT, Sulaymankulov KS (2004) Chemical Journal of Kazakhstan [Himicheskiy Zhurnal

Kazahstana] 1(2):133-138. (in Russian).

4 Sapalova SA (2010) Bulletin of Issyk-Kul University [Vestnik Issyik-kulskogo universiteta] 1:212-217. (In Russian)

5 Frolova EA, Orlova VT, Danilov VP (2008) Russian Journal of Inorganic Chemistry 53: 943-945.

6 Frolova EA, Danilov VP (2009) Russian Journal of Inorganic Chemistry 54:1907-1909.

7 Shaykieva NT, Akhmatova JT (2013) Phase equilibria in the $\mathrm{Zn}(\mathrm{HCOO})_{2}-\mathrm{HCONH}_{2}-\mathrm{H}_{2} \mathrm{O}$ system at $25^{\circ} \mathrm{C}\left[25^{\circ} \mathrm{C}\right.$ da $\mathrm{Zn}(\mathrm{HCOO})_{2}-\mathrm{HCONH}_{2}-\mathrm{H}_{2} \mathrm{O}$ sistemasyindagyi fazalyik te], Abstracts of the Republic Scientific and Practical Conference "Chemistry. Chemical technology. Problems and Prospects" [Respublikanskaya nauchno-prakticheskaya konferentsiya: «Himiya. Himicheskaya tehnologiya. Problemyi i perspektivyi»], Bishkek, Kyrgyzstan, In Press (in Russian).

8 Shvartsenbakh G, Flashka G (1970) Complexometric titrations [Kompleksonometricheskoe titrovanie]. Himiya, Moscow, Russia. (In Russian)

9 Miheeva VI (1975) Method of physical chemical analysis in inorganic synthesis [Metod fiziko-himicheskogo analiza v neorganicheskom sinteze]. Nauka, Moscow, Russia. (In Russian)

10 Tursunalieva KS, Akhmatova ZhT, Sulaymankulov KS (2000) Collection of articles of Biology-Soil Institute of the National Academy of Sciences of Kyrgyz Republic. Study of Kyrgyzstan's wildlife [Sbornik nauchnyih trudov Biologo-pochvennogo instituta NAN KR. Issledovanie zhivoy prirodyi Kyirgyizstana], Bishkek. P.160-164 (in Russian).

11 Imanakunov BI, Kim TP, Baydinov T (1986) Reactions of formamide and dimethylformamide with inorganic salts [Reaktsii formamida i dimetilformamida s neorganicheskimi solyami]. Ilim, Frunze, Kyrgyzstan. P.178. (In Russian) 